\title{
A note from the editor
}

Our journal is enriched by writings that expand the parameters of our field and challenge conventional definitions of Latinidades. In this spirit, this special issue features compelling articles that examine the experiences of Indigenous migrants in the US. Because the struggles of transnational Indigenous peoples are often missing from discussions within Latino studies, I am grateful to guest editors Maylei Blackwell and Luis Urrieta, Jr. for curating an exciting set of articles addressing "Critical Latinx Indigeneities." This innovative framework makes clear that the Indigenous migrant experience is best approached through an analytic located at the intersections of Latino studies, Native studies, and Latin American studies. This special issue brings together interdisciplinary and diverse methodologies to consider nuanced Indigenous epistemologies and innovative forms of activism. The vivencias that complement the articles offer multi-layered, moving and insightful personal reflections on Indigenous Latinidades. I anticipate that the essays in this special issue will inspire enthusiastic dialogue and engagement and may also motivate the rethinking of multiple fields. Enjoy! 